\title{
Analgesic effect of Hypericum perforatum, Valeriana officinalis and Piper methysticum for orofacial pain
}

\author{
Luciana Cristina Nowacki ${ }^{1}$, Paulo Roberto Worfel ${ }^{1}$, Paulo Francisco Arant Martins ${ }^{2}$, \\ Rosane Sampaio dos Santos ${ }^{2}$, José Stechman-Neto ${ }^{2}$, Wesley Mauricio de Souza ${ }^{2,3}$
}

\author{
${ }^{1}$ Universidade Tuiuti do Paraná - UTP, Dental School, Department of Pharmacology, Curitiba, PR, Brazil \\ 2Universidade Tuiuti do Paraná - UTP, Dental School, Graduate program in Communication Disorders, Curitiba, PR, Brazil \\ 3Universidade Federal do Paraná - UFPR, Pharmacy School, Department of Clinical Analysis, Curitiba, PR, Brazil
}

\begin{abstract}
Aim: To evaluate in vivo the association of hypericum (Hypericum perforatum), valerian (Valeriana officinalis) and kava (Piper methysticum) with analgesia by assessing their effects in reducing orofacial pain as well as the possible hepatic, hematologic and biochemical alterations induced by regular administration of these extracts. Methods: Orofacial pain was induced in mice with the administration of $2.5 \%$ formalin in the upper lip. After $60 \mathrm{~min}$, the animals were treated with saline, carbamazepine and hydroalcoholic plant extracts. The nociceptive intensity was determined by the timing at which the animal remained rubbing the injected area. To assess the hepatotoxic effect, mice were chronically treated for 25 days with saline, carbamazepine and hydroalcoholic extract. The animals were euthanized and the liver weighed, followed by a differential count of leukocytes and measurement of alanine transaminase and alkaline phosphatase. Results: The evaluation of analgesic activity in phase 1 reduced the time of rubbing compared to the control by $86 \%(0.05$ $\mathrm{mL} / 10 \mathrm{~g})$ and $76 \%(0.10 \mathrm{~mL} / 10 \mathrm{~g})$. In phase 2, the extracts reduced rubbing time by $94 \%$ and $85 \%$, respectively. In the evaluation of alkaline phosphatase, the groups treated with extracts at doses of $0.05 \mathrm{~mL} / 10 \mathrm{~g}$ and $0.1 \mathrm{~mL} / 10 \mathrm{~g}$ increased by $16.1 \%$ and $9.5 \%$ compared to the control group and a reduction of $8.5 \%$ and $9.1 \%$ in the evaluation of alanine transaminase respectively. It was demonstrated that in the differential counts showed an increase in eosinophils in the treated group with $0.05 \mathrm{~mL} / 10 \mathrm{~g}$. Conclusions: The use of hydroalcoholic extract of the associated plants reduced the orofacial formalin-induced pain with better results than carbamazepine, at both the neural conductor level of pain (phase 1) and in inflammatory or later pain (phase 2) without presenting hepatotoxicity. The observed eosinophilia is suggestive of a phenomenon called hormesis.
\end{abstract}

Keywords: temporomandibular joint disorders; facial pain; hypericum; valerian; kava.

Received for publication: January 12, 2015 Accepted: March 17, 2015

Correspondence to: Wesley Mauricio de Souza Campus Prof. Sydnei Lima Santos (Barigui) Rua Sydnei A. Rangel Santos, 238 CEP: 82010-330 - Curitiba, PR, Brazil Phone: +554196868656

E-mail: wesley.souza@utp.br

\section{Introduction}

Orofacial pain is the field of dentistry devoted to the diagnosis and management of chronic and complex facial pain, and oromotor disorders ${ }^{1-2}$. It may be defined as pain localized in the region above the neck, in front of the ears and below the orbitomeatal line, as well as pain in the oral cavity ${ }^{3}$, and is widely prevalent in the community. Orofacial pain, like pain elsewhere in the body, is usually the result of tissue damage and the activation of nociceptors, which transmit a noxious stimulus to the brain. However, due to the rich innervations of the head, 
face and oral structures, orofacial pain entities are often very complex and can be difficult to diagnose ${ }^{4}$.

Patients with orofacial pain seek a variety of clinicians, including headache physicians, dentists, maxillofacial surgeons, otolaryngologists, neurologists, chronic pain clinics, psychiatrists and related health professionals such as physiotherapists and psychologists ${ }^{5-6}$. Orofacial pain is associated with significant morbidity and high levels of health care use ${ }^{6}$. Because of the wide variety of conditions, many different synthetic classes of drugs are used ${ }^{7}$.

Currently, professionals and official programs worldwide have advised the use of medicinal plants for the treatment of several common diseases ${ }^{8}$. Brazil has a very large number of native plant species that are considered medicinal, but many do not have any scientific assessment of their medicinal potential, which is essential to be used safely by the population?

The search for new drugs has consistently been an effective and safe alternative in reducing neuropathic pain and chronic inflammation. Kava (Pyper methysticum), hypericum (Hypericum perforatum) and valerian (Valeriana officinalis) mainly composed of kavalactones, hypericin and valeric acids, respectively, are described in the literature as plants that present several therapeutic properties such as antidepressants and antiinflamatories ${ }^{10}$. However, they can significantly harm the body when consumed chronically and in associated use with other plants ${ }^{11}$. Health professionals prescribe these plant extracts at low doses to patients with temporomandibular disorder with significant improvements in chronic pain. There are many studies showing the therapeutic effects of these three plants separately ${ }^{10}$, but there are few studies concerning the association of them in treatments related to pain and inflammation.

The purpose of this study was to evaluate in vivo the association of hypericum (Hypericum perforatum), valerian (Valeriana officinalis) and kava (Piper methysticum) with analgesia by assessing their effects in reducing orofacial pain as well as the possible hepatic, hematologic and biochemical alterations induced by regular administration of these extracts.

\section{Material and methods}

\section{Extract preparation}

Alcoholic extracts of Valeriana officinalis $10 \%$ (equivalent to $0.8 \%$ of valeric acid), Hypericum perforatum $10 \%$ (equivalent to $0.27-0.33 \mathrm{mg}$ of hypericin), and Piper methysticum $10 \%$ (equivalent to $22.5 \mathrm{mg}$ of kavalactones) were used. The dyes were commercially available in the city of Colombo, PR, Brazil, along with the product label and technical certification. The alcohol extracts were mixed at a ratio of 3:1:0.5, respectively, and evaporated in an air circulating oven until complete dryness and re-suspended in sterile distilled water at a concentration of $100 \mathrm{mg} / \mathrm{mL}$. After sterilization by a $0.22 \mu \mathrm{m}$ pore-size filter, aliquots were stored at $-20^{\circ} \mathrm{C}$.

\section{Animals}

Experiments were performed on male Swiss albino mice (30-40 g), obtained from the Production and Research Center of Immunobiology (CPPI) in Piraquara, PR, Brazil, where they were kept in a temperature-controlled room $\left(21 \pm 2{ }^{\circ} \mathrm{C}\right)$, with light/dark cycles of 12 hours each, and were allowed free access to food and water. The experiments were performed with the approval of the committee for the use of animals in experiments at Tuiuti University of Paraná under protocol number 008/10P/CEUA/UTP and in accordance with CNS resolution 196/96 and guidelines of the committee for the control and supervision in animal experiments (NIH publication No. 86-23, 1985).

\section{Orofacial Pain Test Induced by Formalin}

The orofacial pain test consisted of the treatment of all groups with $2.5 \%$ formalin $(20 \mu \mathrm{L})$ in the upper lip using a Hamilton's hypodermic syringe. This volume and percentage concentration of formalin were obtained from pilot studies that showed a pain-related biphasic behavioral response (facerubbing) of greater intensity at periods of 0-5 min (first phase) and at 15-30 min (second phase). The nociceptive intensity was determined for each period by counting the time (in s) that the animal rubbed the injected area with the rear and/or front paws, indicative of pain ${ }^{12}$.

To evaluate the analgesic effect of the plant mixture, groups of mice $(n=10)$ were treated orally $60 \mathrm{~min}$ prior to formalin administration with: i) saline $(0.1 \mathrm{~mL} / 10 \mathrm{~g})$; ii) carbamazepine (Medley Pharmaceuticals; $4 \mathrm{mg} / \mathrm{kg}$ ), and iii) the hydroalcoholic extract mix of Hypericum perforatum, Valeriana officinalis and Pyper methysticum at doses of 0.05 - $0.1 \mathrm{~mL} / 10 \mathrm{~g}$. Doses were chosen by previous studies reported in the literature for general plants ${ }^{13-15}$.

\section{Hepatotoxicity Study}

To assess hepatotoxic effect of the plant combination, the groups of mice $(n=10)$ were treated orally for 25 consecutive days using respectively: i) saline $(0.1 \mathrm{~mL} / 10 \mathrm{~g})$, ii) carbamazepine $(4 \mathrm{mg} / \mathrm{kg})$ and iii) the hydroalcoholic extract of the plant combination of Hypericum perforatum, Valeriana officinalis, and Pyper methysticum at doses of 0.05 - $0.1 \mathrm{~mL} / 10 \mathrm{~g}$. On the $26^{\text {th }}$ day the animals were euthanized with ether inhalation, supervised by a veterinarian, their blood collected with EDTA, and their livers removed and weighed. Whole blood smears were performed on slides and stained by the May Grunwald-Giemsa method for differential leukocyte count. Subsequently, the whole blood was centrifuged for $10 \mathrm{~min}$ at $2.500 \mathrm{rpm}$ to separate the plasma and stored in Eppendorf tubes at $2-8{ }^{\circ} \mathrm{C}$ until use. The serum levels of the liver enzymes alanine transaminase (ALT) and alkaline phosphatase (ALP) were assessed in a semi-automated spectrophotometer (TP Analyzer Plus ${ }^{\circledR}$, Thermoplate, China) using LabTest kits and validation with control samples (Qualitrol Company LLC, Fairport, NY, USA).

\section{Statistical Analysis}

Statistical analyses were performed using the statistical packages JMP (version 8.0; SAS Institute Inc., Cary, N.C., USA) and SigmaStat (version 3.5; Systat Software Inc., Erkrath, 
Germany). Results were expressed as mean \pm standard error of the mean (SEM) and used ANOVA followed by Bonferroni test, and the statistical difference was considered to be $\mathrm{p}<0.05, \mathrm{p}<0.01$ or $\mathrm{p}<0.001$.

\section{Results}

In the formalin lip test to determine the analgesic activity of the extract, the obtained data show that the control group showed rubbing time in phase 1 was $44 \pm 7 \mathrm{~s}$ and in phase 2 it was $57 \pm 17$ s. In phase 1 , the carbamazepine cut the rubbing time compared to the control group by $55 \%$ and the extracts in doses $0.05 \mathrm{~mL} / 10 \mathrm{~g}$ and $0.1 \mathrm{~mL} / 10 \mathrm{~g}$ cut rubbing time by $86 \%$ and $76 \%$, respectively, when administered $1 \mathrm{~h}$ before the formalin. In phase 2 of the formalin lip test, the carbamazepine reduced the rubbing time by $60 \%$ and the extracts in doses of $0.05 \mathrm{~mL} / 10 \mathrm{~g}$ or 0.1 $\mathrm{mL} / 10 \mathrm{~g}$ by $94 \%$ and $85 \%$, respectively (Figure 1).

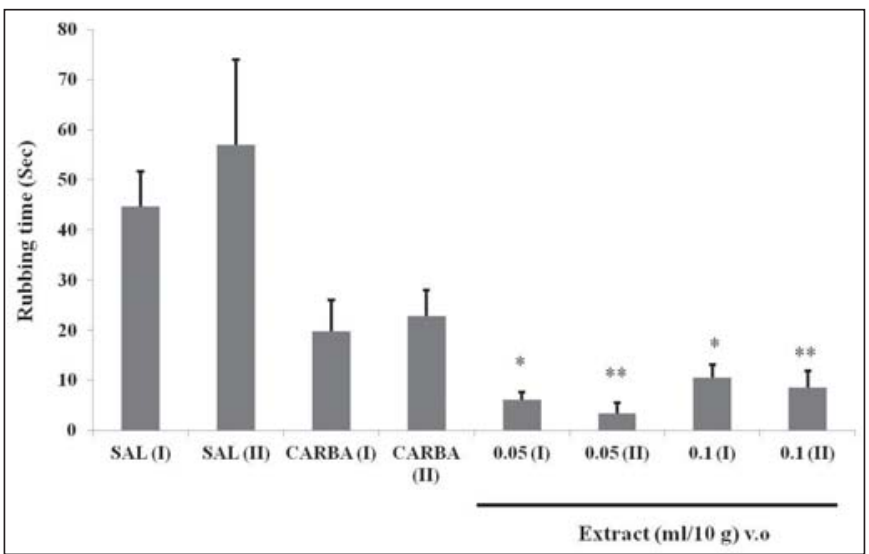

Fig. 1. Effect of hydroalcoholic extract of plant on formalin-induced orofacial pain related face rubbing response in mice. Saline (SAL $-\mathrm{mL} / 10 \mathrm{~g}$ ), carbamazepine (CARBA $-\mathrm{g} / \mathrm{Kg}$ ) or hydroalcoholic extract was administered orally $1 \mathrm{~h}$ before formalin $2.5 \%$ injection $(20 \mu \mathrm{L})$ into the vibrissa pad. (I) Phase $1(0-5 \mathrm{~min})$ and (II) phase 2 (15-30 $\mathrm{min})$ after formalin injection. Each value represents the means \pm SEM of 10 animals. ${ }^{*} p<0.01,{ }^{* *} p<0.001$ compared to control (ANOVA followed by Bonferroni's test).

The liver evaluation results showed that the chronic use of the combination of plants when showed no hepatotoxicity. In assessing the alkaline phosphatase (ALP) treated with the saline control group, amounts were $62.3 \pm 19.5 \mathrm{U} / \mathrm{L}$. These values decreased by $3 \%$ in the group treated with carbamazepine and the groups treated with extracts in volumes of $0.05 \mathrm{~mL} / 10 \mathrm{~g}$ and $0.1 \mathrm{~mL} / 10 \mathrm{~g}$ increased the values by $16.1 \%$ and $9.5 \%$, respectively (Figure $2 \mathrm{~A})$. In the evaluation of the control group, ALT values were $60.31 \pm 10.55 \mathrm{U} / \mathrm{L}$, the group treated with carbamazepine decreased by $12.25 \%$, and the groups treated with extracts decreased by $8.5 \%$ and $9.1 \%$ (Figure 2B). In assessing the weights of the livers, the control group had values of $1.83 \pm 0.16 \mathrm{~g}$, the group treated with carbamazepine showed a $12.7 \%$ increase of these values, and the groups treated with the plant combination decreased by $13.1 \%$ and $5.3 \%$ with no significant differences (Figure 2C). These variations in the figures for liver weight without statistical differences can be justified by the difference in weight between the groups of animals, ranging from $38.1 \pm 2.76$ for the group treated with carbamazepine to $32.1 \pm 2.64$ for the group treated with a dose of $0.05 \mathrm{~mL} / 10 \mathrm{~g}$ (Figure 2D).

The neutrophil count for the control group treated with saline showed values of $17.92 \pm 0.99 \%$, the group treated with carbamazepine showed an increase of $1.67 \%$, and values in the groups treated with extracts at doses of $0.05 \mathrm{~mL} / 10 \mathrm{~g}$ and $0.1 \mathrm{~mL} / 10 \mathrm{~g}$ had decrease of $18.90 \%$ and $9.49 \%$, respectively. In the eosinophil count, the control group had values of $1.1 \pm 0.49 \%$, the group treated with carbamazepine had values $9.09 \%$ lower, and the group treated with the plant extract at a dose of $0.05 \mathrm{~mL} / 10 \mathrm{~g}$ showed increased values by $172,7 \%$, while the group treated with $0.1 \mathrm{~mL} / 10 \mathrm{~g}$ dosage decreased by $27.27 \%$. In the monocyte count, the control group had values of $1.7 \pm 0.7 \%$, the group treated with carbamazepine showed an increase of $58.82 \%$, and values in the groups treated with $0.05 \mathrm{~mL} / 10 \mathrm{~g}$ and $0.1 \mathrm{~mL} / 10 \mathrm{~g}$ presented reductions of $23.52 \%$ and $17.64 \%$, respectively. In the lymphocyte count, the control group showed values of $79.20 \pm 1.22 \%$, the group treated with carbamazepine decreased those values by $1.38 \%$, and the groups treated with the extracts showed $2.52 \%$ and $2.27 \%$ higher values, respectively, for the dosages of $0.05 \mathrm{~mL} / 10 \mathrm{~g}$ and $0.1 \mathrm{~mL} / 10$ g. The results of this study showed that neutrophils, monocytes and lymphocytes remained at normal levels in different cell groups with no significant difference, but there was an increase in eosinophils in the group treated with a dose of $0.05 \mathrm{~mL} / 10 \mathrm{~g}$ of extract presenting a statistically significant difference $(\mathrm{p}<0.05)$ (Table 1$)$.

\section{Discussion}

The mice orofacial formalin test is a useful pre-clinical model of inflammatory trigeminal pain for evaluating antinociceptive activity of analgesics and their combinations. Injection of formalin in the mice lip induces stereotyped response (rubbing), consisting of two distinct phases: a first "phasic", phase and a second "tonic" phase ${ }^{16}$. The orofacial region is the body area most densely innervated by the trigeminal nerve and focuses some of the most common acute pains ${ }^{17}$. The test is a widely accepted model of tonic pain in the corresponding region, which allows for the study of both behavioral and neurophysiological aspects of this pain condition ${ }^{18}$.

The present study demonstrated that the used associated plants reduced formalin-induced orofacial pain with better results than carbamazepine, a drug used to treat neuropathic pain. Carbamazepine is an anticonvulsant that inhibits synaptic depolarization in the pain conduction pathway and limits the repetitive firing of action potentials evoked by persistent depolarization by slowing down the recovery of sodium channels ${ }^{19-20}$ and has been used for its effectiveness in about $60 \%$ to $80 \%$ of patients ${ }^{21}$. Moreover, the results for the evaluation of hepatic markers (ALT and ALP) did not differ significantly between the treatments and the hematological evaluation showed eosinophilia in the group treated with the lower dose $(0.05 \mathrm{~mL} / 10 \mathrm{~g})$. 

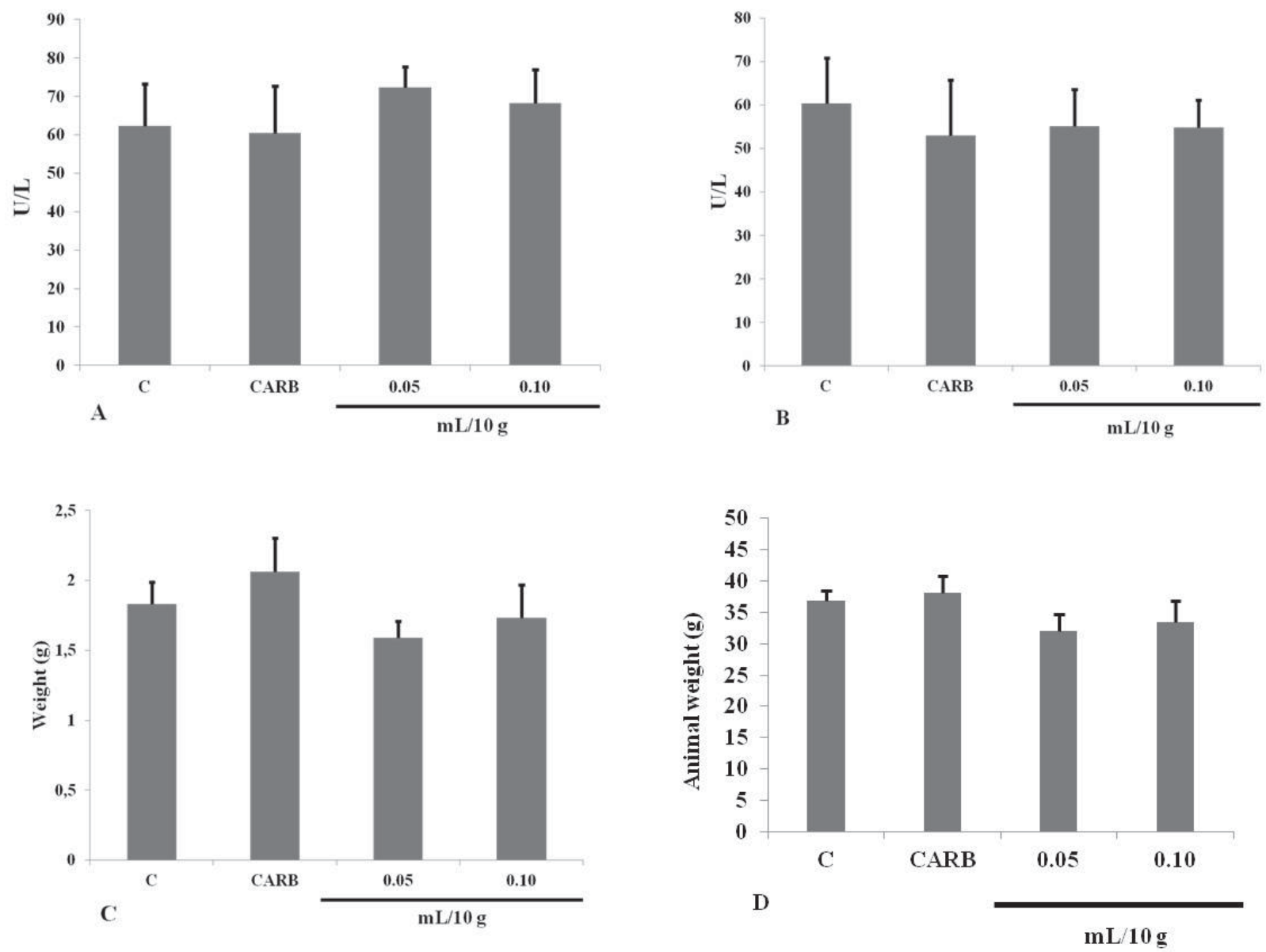

Fig. 2. Absolute values of Alkaline phosphatase (A), Alanine transaminase (B), liver weight (C), and Animal weight (D) in mice in the control groups (C - Saline $\mathrm{mL} / 10 \mathrm{~g}$ ) carbamazepine (CARB - mg/kg), and extracts in doses of $0.05 \mathrm{~mL} / 10 \mathrm{~g}$ and $0.1 \mathrm{~mL} / 10 \mathrm{~g}$ after chronic treatment for 25 days (p.0.). The results are expressed in mean \pm SEM $(n=10) .{ }^{*} p<0.05$ compared to control (ANOVA followed by Bonferroni's test).

Table 1. Values of neutrophils, eosinophils, lymphocytes, and monocytes in groups treated with saline, carbamazepine, extracts in doses of $0.05 \mathrm{~mL} / 10 \mathrm{~g}$ and $0.1 \mathrm{~mL} /$ $10 \mathrm{~g}$ expressed in mean \pm SEM $(\mathrm{n}=10)$. ANOVA test followed by Bonferroni's test $\left({ }^{*} \mathrm{p}<0.05\right)$.

\begin{tabular}{lcccc}
\hline & Neutrophils (\%) & Eosinophils (\%) & Lymphocytes (\%) & Monocytes (\%) \\
Saline & $17.9 \pm 0.99$ & $1.1 \pm 0.49$ & $79.2 \pm 1.22$ & $1.7 \pm 0.70$ \\
Carbamazepine & $18.2 \pm 3.25$ & $1.0 \pm 0.36$ & $78.1 \pm 3.19$ & $2.7 \pm 0.53$ \\
$0.05 \mathrm{~mL} / 10 \mathrm{~g}$ & $14.5 \pm 1.72$ & $3.0 \pm 0.77^{*}$ & $81.2 \pm 2.04$ & $1.3 \pm 0.42$ \\
$0.10 \mathrm{~mL} / 10 \mathrm{~g}$ & $16.2 \pm 2.59$ & $0.8 \pm 0.37$ & $81.0 \pm 2.84$ & $1.4 \pm 0.45$ \\
\hline
\end{tabular}

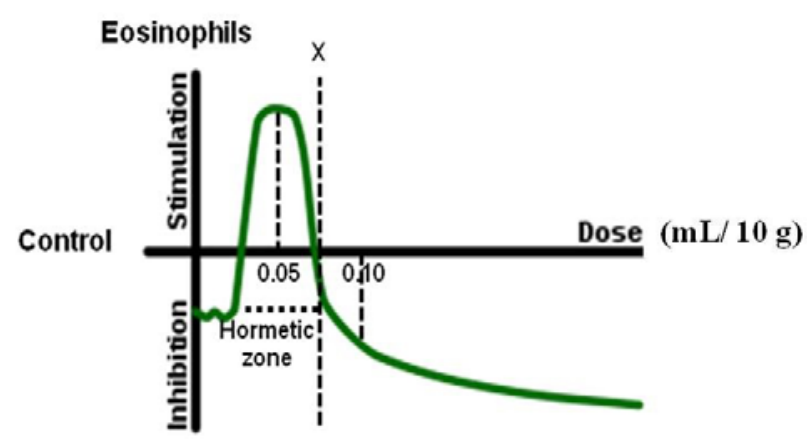

Fig. 3. Dose-response curve showing the quantitative features of hormesis 
There are few studies involving the three plants that were chosen to use a ratio for the plants of $3: 1: 0.5$, respectively, in order to reduce individual toxicities and seek a synergistic analgesic effect in mice. The proportions of the drugs used account for about $1 / 3$ of the therapeutic dose. In this sense, for the analgesia induced by the formalin test in the trigeminal nerve, were obtained significant results because the plant combination reduced direct formalin pain in the pain conducting neuron (trigeminal), called phase 1, and reduced inflammatory or later pain, called phase 2 , which is the release of pro-inflammatory products such as bradykinin, TNF and prostagladins ${ }^{22}$.

Studies have shown that Piper methysticum, Valeriana officinalis and Hypericum perforatum used separately exhibit antidepressant, muscle relaxant, anti-inflammatory and sedative properties ${ }^{10}$. Alcoholic kava extract inhibits cyclooxygenase 1 and 2 . In addition to having a variety of effects on the central nervous system, including anxiolytic, sedative, anticonvulsant, local anesthetic, spasmolytic and analgesic properties, probably for its inhibitory effects of $\mathrm{NF}-\mathrm{kB}$, it is an important factor in the anti-inflammatory activity of the cascade of prostaglandins ${ }^{23}$. Yao et al. ${ }^{24}$ demonstrated the analgesic effect of kava on abdominal contortions and formalin tests on rats' paws. Recent studies suggest that valerian reduces dopamine transport for chronic pain in rats. Valeriana officinalis has anxiolytic, antidepressant and myorelaxing properties, important factors in cases of mild insomnia, orofacial pain and temporomandibular disorders ${ }^{25}$. The alcoholic and methanolic extracts of hypericum have analgesic and anti-inflammatory effects in formalin and abdominal contortions tests ${ }^{26}$.

Hepatic changes can occur due to reactions involving cytochrome $\mathrm{P} 450^{27-28}$. Liver damage may be hepatocellular, causing increased serum of the alanine aminotransferase (ALT) and aspartate aminotransferase (AST) enzymes, or cholestatic, leading to increased bilirubin, alkaline phosphatase (ALP) and gamma-GT ${ }^{29}$. Studies have shown that chronic use of valerian causes hepatic toxicity in addition to side effects such as dyspepsia, allergic skin reactions, headache, and agitation ${ }^{30}$. Kava may exacerbate the status of patients with liver failure and hepatitis in those with a history of recurrent liver disease. There are reports of acute hepatitis with severe hepatocellular necrosis, requiring liver transplantation in patients after ingestion of kava extract doses considered to be therapeutic. In susceptible patients, some symptoms may appear after a short time. Evaluations of liver function tests indicate changes in the results after 1-2 months of use, with symptoms of hepatomegaly and early encefalopatia ${ }^{10}$. Hypericum also has reports of liver damage in rat fetuses whose mothers were exposed to hypericin ${ }^{11}$. Despite reports of hepatic disorders related to the use of hypericum, kava and valerian in therapeutic doses of $900 \mathrm{mg} / \mathrm{Kg}, 300 \mathrm{mg} / \mathrm{Kg}$ and $150 \mathrm{mg} / \mathrm{Kg}$ respectively ${ }^{29-30}$, the obtained results showed that the use of combined smaller doses (1/3 of the therapeutic doses) are not detrimental considering the biochemical parameters.

Eosinophilia in the group treated with the lower dose $(0.05 \mathrm{~mL} / 10 \mathrm{~g})$ can be explained by a phenomenon called hormesis. This is a term for generally favorable biological responses to low exposures to stressors. Chemical substances like, for example, kavalactones, hypericin and valeric acid, or toxins showing hormesis thus have the opposite effect in small doses as in large doses resulting in either a J-shaped or an inverted U-shaped dose response (Figure 3). A related concept is Mithridatism, which refers to the willful exposure to a substance in an attempt to develop immunity against $i^{31}$. Evidence is presented which supports the conclusion that the hormetic dose-response model is the most common and fundamental in the biological and biomedical sciences, being highly generalized across biological model, measured endpoint and chemical class and physical agent. The hormesis model of dose response is vigorously debated ${ }^{32}$. The biochemical mechanisms by which hormesis works are not well understood. The conjecture is that low doses of stressors may activate the repair mechanisms of the body. The repair process fixes not only the damage caused by the chemical substance, but also other low-level damage that may have accumulated before, without triggering the repair mechanism.

Kava (Piper methysticum), Hypericum (Hypericum perforatum) and Valerian (Valeriana officinalis) are described in the literature as plants with several biological properties, but that may present severe hepatic impairment related to chronic consumption and in combination with other plants. In low doses, they are prescribed by health professionals to patients with orofacial pain of nociceptive origin, such as pain of temporomandibular origin and bucofacial neuropathic pain with significant improvements in levels of chronic pain.

In conclusion, this study is the first demonstrated that p.o pretreatment of an association of hypericum (Hypericum perforatum), valerian (Valeriana officinalis) and kava (Piper methysticum) reduced the nociceptive response in both the first and the second phases in orofacial formalin test. In addition, there were no changes in liver markers and white blood cells count, but one eosinophilic at the lowest dose of extract. The authors believe that this research contributes to the health knowledge in the area of orofacial pain treatment by providing data for possible use of these plants as adjuvants or substitutes of the currently used drugs because of their proven analgesic and anti-inflammatory powers. It is important to mention that the present study has some limitations. Studies comprising other analgesic activity tests, histopathological studies and pro-inflammatory markers are required to understand the involved mechanisms. Taken together, these observations will provide an insight for similar future studies.

\section{References}

1. American Academy of Orofacial Pain. The scope of TMD/orofacial pain (head and neck pain management) in contemporary dental practice. Dental Practice Act Committee of the American Academy of Orofacial Pain. J Orofac Pain. 1997; 11: 78-83.

2. Coderre TJ, Katz J, Vaccarino AL, Melzack R. Contributions of central neuroplasticity to pathological pain: review of clinical and experimental evidence. Pain; 1993; 52: 259-85.

3. Shephard M K, MacGregor EA, Zakrzewska JM. Orofacial Pain: A Guide for the Headache Physician. Headache. 2014; 54: 22-39. 
4. Vickers ER, Cousins MJ. Neuropathic orofacial pain part 1—prevalence and pathophysiology. Aust Endod J. 2000; 26: 19-26.

5. Bell GW, Smith GL, Rodgers JM, Flynn RW, Malone CH. Patient choice of primary care practitioner for orofacial symptoms. Br Dent J. 2008; 204: 669-673.

6. Wirz S, Ellerkmann RK, Buecheler M, Putensen C, Nadstawek J, Wartemberg HC. Management of chronic orofacial pain:A survey of general dentists in German university hospitals. Pain Med. 2010; 11: 416-24.

7. Steven Ganzberg, DMD. Pain Management Part II: Pharmacologic Management of Chronic Orofacial Pain. Anesth Prog. 2010; 57: 114-9.

8. Schveitzer MC, Zoboli EL. Role of complementary therapies in the understanding of primary healthcare professionals: a systematic review. Rev Esc Enferm USP. 2014; 48: 184-91.

9. Soejarto DD. Biodiversity prospecting and benefit-sharing: perspectives from the field. J Ethnopharmacol. 1996; 51: 1-15.

10. Posadizki P, Watson LK, Ernst E. Adverse effects of herbal medicines: an overview of systematic reviews. Clin Med. 2013; 13: 7-12.

11. Bruner NR, Anderson KG. Discriminative-stimulus and time-course effects of kava-kava (Piper methysticum) in rats. Pharmacology, Biochemistry and Behavior. 2009; 92: 297-303.

12. Feies-Szabo A, Bohar Z, Nagy-Grocz G, Vamos E, Tar L, Podor B, et al. Effect of probenecid on the pain-related behaviour and morphological markers in orofacial formalin test of the rat. CNS Neurol Disord Drug Tergets. 2014 Auyg 6; doi: 10.2174/1871527313666140806152955.

13. Hattesohl M, Feistel B, Sievers $H$, Lehnfeld R, Hegger M, Winterhoff $H$. Extracts of Valeriana officinalis L. s.I. show anxiolytic and antidepressant effects but neither sedative nor myorelaxant properties. Phytomedicine. 2008; 15: 2-15.

14. Perazzo FF, Lima ML, Padilha MM, Rocha LM, Sousa PJC, Carvalho JC. Anti-inflammatory and analgesic activities of Hypericum brasiliense (Willd) standardized extract. Braz J Pharmacog. 2008; 18: 320-5.

15. Tasleem F, Azhar I, Ali SN,Perveen S, Mahmood ZA. Analgesic and antiinflammatory activities of Piper nigrum L. Asian Pac J Trop Med. 2014: 7S1: S461-8. doi: 10.1016/S1995-7645(14)60275-3.

16. Raboisson P, Dallel R. The orofacial formalin test. Neurosci Biobehav Rev. 2004; 28: 219-26.

17. Bonjardim LR, Silva AM, Oliveira MG, Guimarães AG, Antoniolli AR, Serafini MR, et al. Sida cordifolia leaf extract reduces the orofacial nociceptive response in mice. Phytother Res. 2011; 25: 1236-41.

18. Clavelou P, Pajot J, Dallel R, Raboisson P. Application of the formalin test to the study of orofacial pain in the rat. Neurosci Lett. 1989; 103: 349-53.

19. Koppenol WH. Concurrent Cooperativity and Substrate Inhibition in the Epoxidation of Carbamazepine by Cytochrome P450 3A4 Active Site Mutants Inspired by Molecular Dynamics Simulations. Biochemistry. 2014; doi: $10.1021 / b i 5011656$.

20. Brunton LL. Goodman \& Gilman: The pharmacological basis of therapeutics. Rio de Janeiro: McGraw-Hill; 2012.

21. Góes TMPL, Fernandes RSM. Trigeminal neuralgia: diagnosis and treatment. Int J Dent. 2008; 7: 104-11.

22. Carvalho WA; Lemônica L. Specific Cyclooxygenase-2 InhibitorAnalgesics: Therapeutic Advances. Rev Bras Anestesiol. 1998; 48: 137-58.

23. ShaikAA, Hermanson DL, Xing $C$. Identification of methysticin as a potent and non-toxic NF-jB inhibitor from kava, potentially responsible for kava's chemopreventive activity. Bioorg Med Chem Lett. 2009; 19: 5732-36.

24. Yao CY, Wang J, Dong D, Qian FG, Xie J, Pan SL. Laetispicine, an amide alkaloid from Piper laetispicum, presents antidepressant and antinociceptive effects in mice. Phytomedicine. 2009; 16: 823-9.

25. Hattesohl M, Feistel B, Sievers H, Lehnfeld R, Hegger M, Winterhoff H. extracts of Valeriana officinalis $L$. show anxiolytic and antidepressant effects but neither sedative nor myorelaxant properties. Phytomedicine. 2008; 15: 2-15.

26. Sanchez-Mateo CC, Bonkanka CX, Hernandez-Perez M, Rabanal RM. Evaluation of the analgesic and topical anti-inflammatory effects of Hypericum reflexum L. fil. J Ethnopharmacol. 2006; 107: 1-6.
27. Bertolami MC. Mechanisms of hepatotoxicity. Arq Bras Cardiol. 2005; 85: 25-7.

28. Rodrigues MG, Mendonça MM, De Paula JAM. Analysis of rational use of Hypericum perforatum from the profile of the prescriptions dispensed in pharmacies Anapolis-GO.Rev Eletron de Farm. 2006; 3: 45-52.

29. Pearl PL, Drillings IM, Conry JA. Herbs in epilepsy: evidence for efficacy, toxicity, and interactions. Semin Pediatr Neurol. 2011; 18: 203-8.

30. Prasad R, Naime M, Routray I, Mahmood A, Khan F, Ali S. Valeriana jatamansi partially reverses liver cirrhosis and tissue hyperproliferative response in rat. Methods Find Exp Clin Pharmacol. 2010; 32: 713-9.

31. Calabrese EJ. Hormesis and medicine. Br J Clin Pharmacol. 2008; 66: 594-617.

32. Kaiser J. Sipping from a Poisoned Chalice. Science. 2003; 302: 376-9. 